\title{
Dynamic Reflection Behaviors of Weld Pool Surface in Pulsed GTAW
}

\author{
This study analyzed the residual oscillation in pulsed GTAW to determine \\ the weld pool penetration state based on the dynamic reflection \\ behaviors of the weld pool surface as an oscillating mirror
}

BY J. S. CHEN, J. CHEN, K. ZHANG, Z. FENG, AND Y. M. ZHANG

\begin{abstract}
In this paper, a method was studied to determine the weld pool penetration based on the dynamic behaviors of the weld pool surface. To this end, relative works were performed to observe, measure, and analyze the development of a weld pool through the imaged laser matrix dots and correlate the changes in the imaged dots to the weld pool penetration. It was found that during partial joint penetration, the imaged dot matrix on the weld pool was clear and bright, but became fuzzier and dimmer when critical/complete joint penetration was reached. Results showed this was related to the root damping force in partial penetration, which obstructed the oscillation of the weld pool and made the surface relatively still for imaging. When critical/complete joint penetration was reached, the root damping force was diminished, and thus the pool surface oscillation was stronger, which led to dimmer and fuzzier images. By quantifying the relation between the image grayness variations with the penetration stages, a method was found for the automated control of the welding process.
\end{abstract}

\section{KEYWORDS}

- Sensor • Process Control/Monitoring • Robotics

- Automation • GTAW

\section{Introduction}

Gas tungsten arc welding (GTAW) is a widely used metal joining process because of its ability to produce high-quality welds and its relatively low equipment cost (Ref. 1). Complete joint penetration of the weld pool is a critical index to evaluate the weld quality for both manual and mechanic/ automatic welding processes. For a skilled welder, he or she can control the weld penetration by observing a weld pool surface change. However, for mechanized/automated welding processes, it is hard to control the weld penetration because there is no effective method to detect the pool penetration.

Weld penetration sensing and control are fundamental issues in automatic welding processes, which have been widely studied for decades. One way to determine complete joint penetration is using a backside sensor to monitor the backside bead width. However, because of the issues in sensor access and motion match between the torch and sensor, the backside sensor method is not a preferred way to detect the weld penetration. Hence, the topside sensing of weld penetration is the mainstream of the studies.

Since the weld pool depth and backside bead width cannot be observed directly by the topside sensor, indirect monitoring methods have to be used. Various techniques have been tried to solve this problem, such as weld pool oscillation, ultrasonic sensing, infrared sensing, arc voltage, and more (Ref. 2). Weld pool oscillation has been studied by Kotecki (Ref. 3), Richardson (Ref. 4), and Hardt et al. (Ref. 5). Ouden et al. (Refs. 6-8) found there is a significant change in the pool oscillation frequency from partial to complete joint penetration. They designed a penetration sensor by monitoring the pool oscillation frequency. The sensor used a relatively large current pulse to stimulate the pool oscillation, and required time to sample signal to determine the oscillation frequency. The capability to detect the penetration in real time was affected. Other researchers have worked on ultrasonic-based weld penetration sensing (Refs. 9-16). While good progress has been made, there are still works that have to be done before the method can be used in manufacturing production. Researchers have also used infrared sensors to measure and analyze the temperature distribution in the weld zone, and the weld penetration is correlated to the infrared characteristics of the infrared image (Refs. 17-20). Further, the variation of the arc voltage has been analyzed to monitor the penetration in GTAW processing (Refs. 7, 21-23). Because of the surface oscillation and pool volume heat expanding, the distance between the tungsten electrode tip and the weld pool surface changes during the development of the weld penetration, such that the arc voltage changes. The development of the arc voltage that reflects the change in the arc length and weld pool surface can thus be analyzed to determine the weld joint penetration. This method is simple, but it is easily affected by the torch height change. Similarly, researchers also monitored the sag of the pool surface change by measuring the shift of the position of the reflection from the pool surface to the projected collimated light (or laser) (Ref. 24).

Although these already developed methods have achieved 
success to some extent, they all have certain limitations, which may restrict their applicability. One significant drawback associated with relatively simple methods is they are one dimensional, i.e., based on analysis of a time series of a scalar signal such as arc voltage signal and arc radiation signal. While one-dimensional methods are, in general, simple and preferable, they may cause delays and are often interruptive. Hence, new techniques are needed and studied.

The University of Kentucky welding research lab recently developed an innovative method to measure the 3D geometry of the weld pool surface (Refs. 25-28). In this method, a matrix dots laser was projected onto the weld pool region. Since the weld pool surface is specular, the laser dots on the weld pool surface were reflected and intercepted by an imaging plane where the intercepted laser dots formed their images. A camera was used to take images of the reflected laser dots on the imaging plane and transmit them to the computer in real time. Through image processing and 3D reconstruction, the dynamic weld pool surface was obtained in real time. Studies (Refs. 29, 30) have shown the effectiveness of such sensing methods through direct control of the 3D weld pool surface for the penetration.

This 3D method can reveal more information about the pool penetration in a shorter period of time. Increasing the dimension of the signal to be analyzed reduces the time needed such that the instantaneous signal can be used. However, despite the success in monitoring the 3D weld pool surface in real time, such a method needs to calculate the reflecting laser dots image and the image processing/ reconstruction algorithm is relatively complex. The accuracy of the measurement also decreases in high-current welding processes because the arc light is extremely bright compared to the reflecting laser dots, which can overshadow the reflection images.

While it is ideal to have a single yet simple solution for all major applications, such a solution remains an extreme challenge. This is because the weld penetration is a state developing underneath the workpiece surface and is thus not conveniently visible or observable. Because of the complexity of the welding process and the variety of the applications, the applicability of indirect methods like all of those that have been studied is subject to limitations. Since the penetration is critical in assuring the weld integrity, a more complex set of solutions needs to be established. As such, a new method was proposed in this study to predict the weld pool penetration.

While previous methods analyzed a time series of arc length, as represented by the arc voltage or arc radiation, to determine the frequency of the oscillation, which is determined by the state of the weld penetration, the new method proposed here indirectly detected the state of the oscillation through its effect on the brightness of the laser dots reflected from the weld pool surface, i.e., a laser dot reflected from a more seriously oscillating pool surface changes its reflection direction more significantly within a given small time interval, resulting in a less clear reflection image. As a result, the oscillation state, which is correlated to the state of the weld penetration, could be determined by the brightness of the 2D reflection images. The detection of the oscillation state changed from not being real time to being real time through the trade of dimension for time. We wish to also mention that there were studies that measured the oscilla-

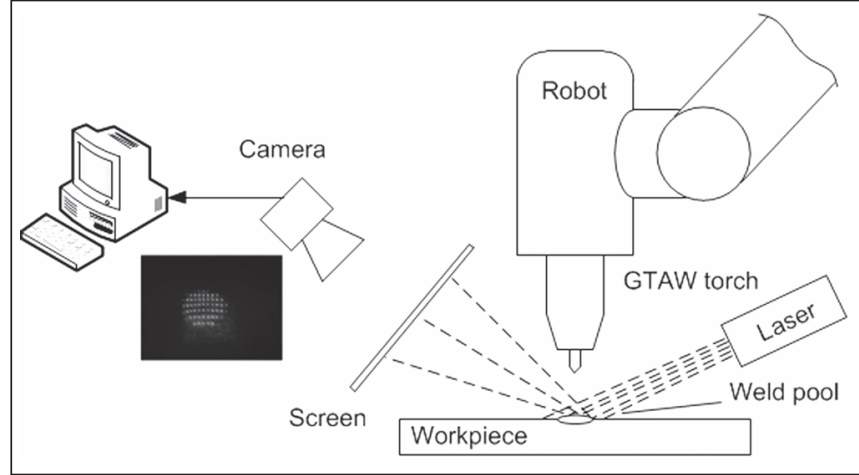

Fig. 1 - Experimental system.

tion amplitude to determine the weld pool status. However, while such a method shared a certain similarity with the method proposed in this study, it still required at least a full oscillation period to determine the oscillation amplitude. For the method proposed, the clearness of the reflection image was imaged instantaneously in a single frame.

\section{Experimental System Setup and Noninterruptive Oscillation}

The schematic diagram of the system measuring the reflection from the weld pool surface is shown in Fig. 1. A UR5 robot carries the GTAW torch. A 20-mW illumination laser (Lasiris SNF-519-685-20) with a wavelength of $685 \mathrm{~nm}$ generated a $19 \times 19$ dot matrix structured light, which was projected onto the weld pool region. Since the weld pool surface was specular, it reflected the projected dots. The reflected rays were intercepted by, and formed images on, the imaging plane. A charge-coupled device (CCD) high-speed camera (modified Gazelle's GZL-CL-22C5M-C) sensed these images at 1 frame per ms and transported them to the $P C$ in real time for online analysis and control.

In previous pool oscillation-based methods, an extra large, short-time impulse current was applied at the beginning of each pulse wave to excite the pool to oscillate. The time series of the signal used to analyze the oscillation frequency was acquired after the impulse current was resumed back to the "normal pulse welding current." The process was slightly altered.

In the proposed method, a pulsed current waveform was used to perform pulsed GTAW. The pool was oscillated by the "pulsed welding current waveform" such that the pulsed welding process was not altered in any way. The images were taken during the base current period such that the effect of the arc radiation on the reflection images could be reduced. In addition, only one image frame was taken in each base period with the same delay each time after the current was reduced to the base current. The brightness of the reflection dots will reflect how seriously the pool is oscillating at exactly the same time in each period of the pulse waveform. Comparing the brightness of the reflection dots with those in the previous pulsing periods will tell how the brightness of the reflection dots has been changed, thus how the oscillation of the weld pool has changed. As such, the detection of the pool oscillation state becomes real time. 
Table 1-Experimental Parameters

Welding Parameters

\begin{tabular}{lcc} 
Parameter & Value & Unit \\
\hline Material (Stainless Steel 304L) & 2 & $\mathrm{~mm}$ \\
Arc length & 5 & $\mathrm{~mm}$ \\
Base period time & 3 & $\mathrm{~ms}$ \\
Base period current & 20 & $\mathrm{~A}$ \\
Peak period time & 22 & $\mathrm{~ms}$ \\
Peak period current & $30-120$ & $\mathrm{~A}$ \\
Welding time & variable & $\mathrm{S}$ \\
Shielding gas (Ar) & 15 & $\mathrm{ft}^{3} / \mathrm{h}$ \\
Backside shielding gas (Ar) & 30 & $\mathrm{ft}^{3} / \mathrm{h}$ \\
\hline
\end{tabular}

To further reduce the effect of the arc radiation on the laser dots images, a band-pass filter matching the laser wavelength was used. The PC processed the images in real time for quantitative measurements of the brightness of the images of the reflected laser dots with welding time. The experimental parameters are given in Table 1.

\section{Dynamic Change of the Weld Pool Surface and Its Effect on Imaging}

\section{Surface Morphology of the Weld Pool during Welding}

Figure 2 shows the laser dot matrix projected on the solid workpiece (A) before welding, as well as reflected by the liquid weld pool (B) during welding. Since the surface of the weld pool is specular, the light rays after having been reflected by it can form images on the imaging plane. On the other hand, the surface of the solid workpiece was rough and, consequently, light rays projected on it were scattered in random directions and thus no image could be formed on the imaging plane. Due to this reason, pictures were taken directly from the workpiece when it was needed to study the laser dot images on the solid surface, while they were taken from the imaging plane when studying the effect of the weld pool.

By comparing these pictures, it was easily found that the distances between neighboring imaged dots were much larger when the laser rays were reflected from the weld pool than when they were projected on the solid workpiece. The reflected dots on Fig. 2B have an average distance of $4 \mathrm{~mm}$, while those on the solid workpiece (Fig. 2A) are only about $0.5 \mathrm{~mm}$. This difference indicates the surface of the weld pool is convex, as shown in Fig. 3. In Fig. 3, the distance between the two reflected image dots ( $a$ and $b$ ) on the imaging plane is much larger than the distance between the two dots (a'and b') on the workpiece. In fact, a close examination of the molten stainless steel's density also proves this.

Molten stainless steel has significant thermal expansion compared to its solid state. Matsumoto et al. (Ref. 31) studied 304 stainless steel and obtained the density of molten 304 stainless steel as

$$
\rho=-0.616 \times T+8.11 \times 10^{+3}\left(\mathrm{~kg} / \mathrm{m}^{3}\right)
$$
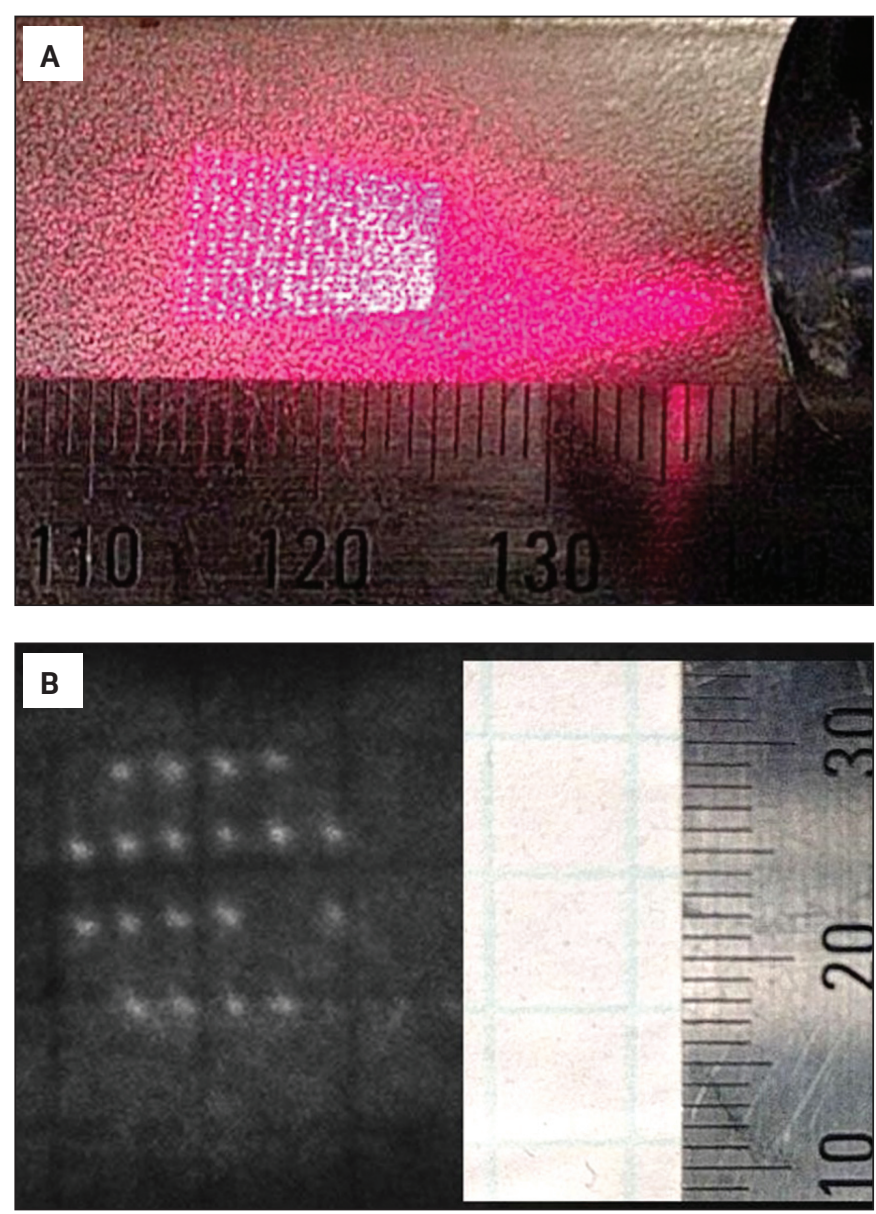

Fig. 2 - Laser dot matrix - A - Projected on the solid workpiece; $B$ - reflected on the image plane by the weld pool.

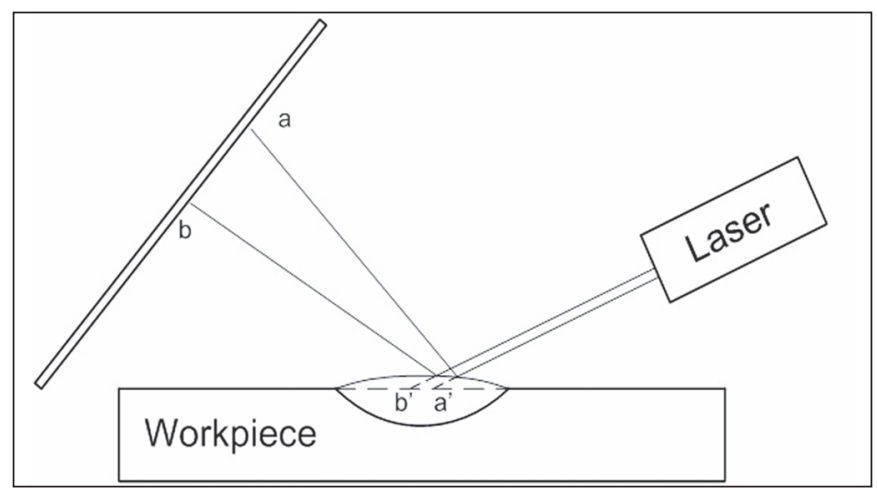

Fig. 3 - Schematic showing the increase in the distances of the imaged dots on a convex surface.

where $T$ is the temperature of the molten liquid metal, which has the range $1823 \sim 2073 \mathrm{~K}$.

This equation shows that the molten stainless steel density is negatively linearly correlated to the temperature, implying that when the stainless steel is melted, its volume will increase. From its solid-state density of $8.11 \times 10^{+3}$ to the molten state density of $6.88 \times 10^{+3}$ (at $2000 \mathrm{~K}$ ), the decrease in density from solid to liquid state was approximately $15 \%$. This indicated the volume of the liquid stainless steel will in- 
crease by $15 \%$. To compensate for the volume change, the liquid weld pool will rise up from its surrounding unmelted workpiece. The end result of this change is a convex weld pool surface. However, after complete joint penetration was reached, the backside metal of the workpiec began to melt. Since the bottom of the weld pool was no longer solid, the weld pool extended beyond the backside surface of the workpiece. Obviously, as the molten metal extends more on the backside, the convexity of the weld pool surface will reduce and the surface may even become concave under the effect of the gravity (at the flat position) and arc pressure. To conclude, the front-side weld pool surface will have such a cycle: elevation, maintenance, and retraction. This characteristic can globally affect the imaging of the dot matrix, regardless of the oscillation of the pool, while the oscillation state will further add additional signatures in the images as will be discussed.

\section{Characteristics of the Weld Pool Oscillation}

The weld pool is a body of liquid metal, and changes in its environment including forces acting on it can cause it to oscillate. Current pulses have been purposely used to change the arc force (although other current-associated forces such as the electromagnetic force will also change accordingly) acting on the weld pool to excite it to oscillate. Den Ouden et al. proposed the following key points to correlate such excited oscillation to the weld penetration in GTAW (Ref. 8): 1) during partial penetration, the oscillation has higher frequencies; 2) during overpenetration, the oscillation has lower frequencies; and 3) during optimal penetration, the oscillation has a frequency in between.

There have been recent studies related to the oscillation frequency to the state of the weld joint penetration using image-based analysis. Shi et al. observed the following for pulsed GTAW (Refs. 32, 33): 1) In partial and complete joint penetrations, a single distinctive oscillation frequency of the weld pool exists in the frequency spectrum; 2) the oscillation frequency in partial joint penetration is obviously higher than that in complete joint penetration; and 3) in critical penetration, the pool oscillation shows a distinct boundary featured for partial and complete joint penetrations, and two distinctive oscillation frequencies occur. Zhang et al. observed that the dynamic behaviors of the weld pool oscillation have direct relationships with the state of the weld joint penetration (Ref. 34).

While all previous studies mentioned a focus on the relationship between the oscillation with the state of the weld joint penetration, this study distinguishes from previous studies by its proposed method to detect the oscillation (and this method makes it possible to detect the oscillation in real time). The idea proposed in this study is whether the brightness of the reflection image can reflect the oscillation state, which is determined by the penetration. As can be seen, the oscillation frequency was replaced by the brightness of the reflected laser dots, and this was possible because they were both determined by the oscillation of the weld pool. Further more, in the previous methods, the oscillation frequency was correlated to the weld penetration for the specific interruptive welding process. Analysis was needed to determine why and how the oscillation of the weld pool in the noninterruptive pulsed GTAW process was determined by the weld penetration.

When the weld pool, thus the reflection mirror of the projected laser dots, oscillates, the reflected laser rays scan in the space. Within the given imaging time, during which the optical signal is integrated by the CCD sensors, a reflected laser dot moves among different pixels on the CCD sensor. The image of the reflected dot will thus be larger but weaker, i.e., fuzzier. A stronger oscillation, higher frequency, and larger amplitude produces a fuzzier image provided the oscillation period is greater than the imaging time. For this study, whose imaging time was $1 \mathrm{~ms}$, it was much shorter than the oscillation period. Hence, the brightness of the reflected laser dots can measure the degree of the oscillation.

To determine why and how the oscillation of the weld pool in the noninterruptive pulsed GTAW process was determined by the weld penetration, an in-depth analysis was needed for the particular oscillation of the weld pool in our noninterruptive pulsed GTAW process, where the peak period was much longer and the base period was only $3 \mathrm{~ms}$. While a periodical change in the welding current between the peak and base values always causes the arc pressure acting on the weld pool to change periodically and thus excites the weld pool to oscillate, the oscillation in this noninterruptive pulsed GTAW during the base period was suppressed by the increased arc pressure after the current quickly switched to the peak current. When the current was switched to the base current, a new oscillation was excited. The argument is the oscillation that affects the weld pool during the imaging time, $1 \mathrm{~ms}$ after the current reduction command signal is sent, should primarily be the oscillations generated in the previous cycle(s) rather than the new one because the current takes time to reduce and $1 \mathrm{~ms}$ is much quicker than the oscillation period. The oscillation that affected the brightness is the "residual oscillation" from the previous cycles rather than the new oscillation.

To be simple, consider the oscillation from the last excitation (current reduction from peak to base) only. First, it is apparent a larger difference in the arc pressure due to a larger current pulse generates a larger initial oscillation. Second, after the current switches to the peak value and maintains at that value, the oscillation will tend to decay because of the damping. Third, the degree of the decay of the oscillation increases with the decay time, which is the peak current period. In this study, the peak current period was fixed, and the base and peak current were fixed. Hence, the residual oscillation that determines the scan of the reflected laser dots during the imaging time was primarily determined by the damping of the oscillation in the proposed method, which was characterized by the noninterruptive pulsed GTAW and the imaging at the fixed time in the base period.

The damping to the oscillation of the weld pool dramatically changed with the weld penetration state: 1) During partial joint penetration where the pool root was solid, the pool only had one free surface, and thus the damping was strong; and 2) when complete joint penetration was reached, the pool root became liquid such that the oscillation has two free surfaces, pool topside and backside; the damping was thus weaker. Of course, a weaker damping tends to lead to a stronger residual oscillation. Since other variables (initial oscillation as determined by the current difference and the 

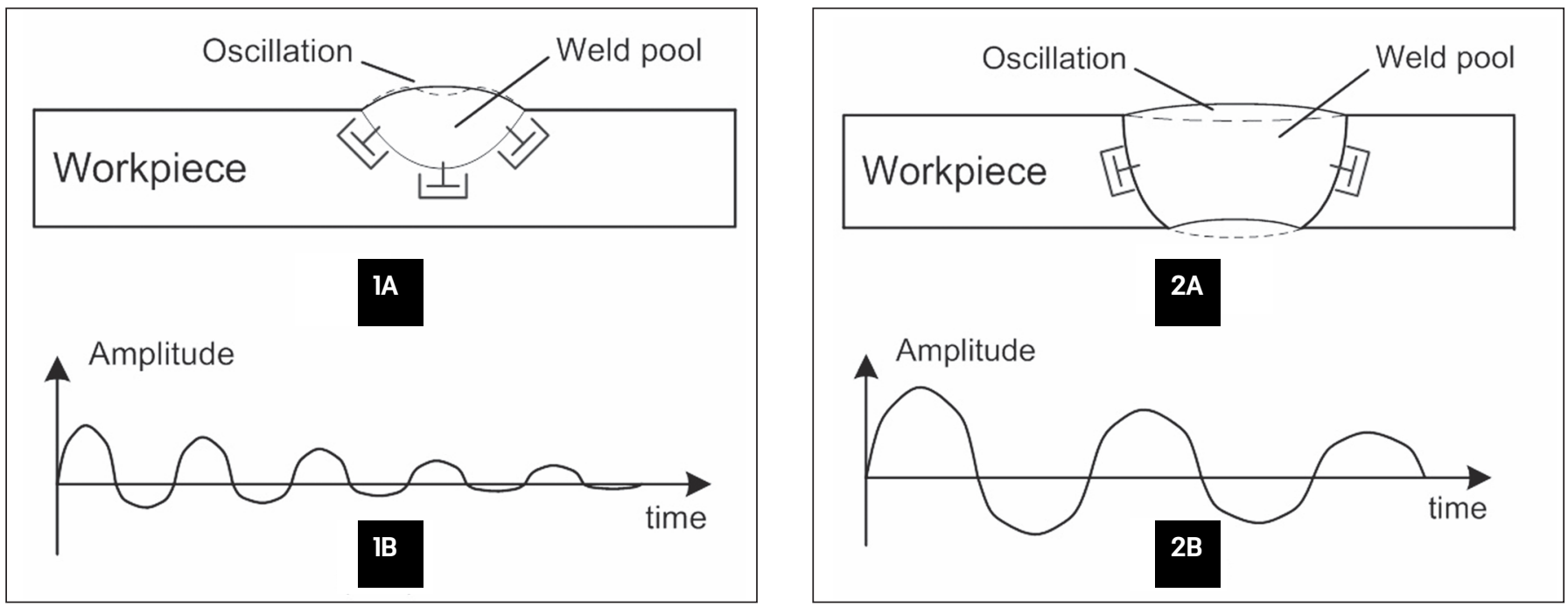

Fig. 4-Schematic of damping forces acting on the oscillating weld pool and the corresponding waveforms.

decay time) were given, the residual oscillation at the imaging time in the proposed method was primarily determined by the pool root, thus the weld penetration. Hence, the brightness of the reflected laser dots was determined by the weld penetration state.

Figure 4(1A) and (2A) shows simplified illustrative models for damping forces acting on an oscillating weld pool in the partial and complete joint penetration states, respectively. The damping forces acting on the sides of the weld pool are typically also present under a complete joint penetration state in GTAW because the pool is partially confined in the vertical direction by the solid workpiece as long as the backside width/diameter of the weld pool is not greater than that in the front side. However, in both cases, the effect of the side-damping forces was relatively small since they were not in the direction of the pool's movement (the oscillation was created in the vertical direction).

The major effect from the damping forces on the oscillation was on the vertical direction. In Fig. 4(1A), the pool is in partial joint penetration. Since the bottom is still solid, the damping force acting at the bottom is much stronger in damping the oscillation than the side damping force as it is in a different direction of the pool's movement. To illustrate the difference, the bottom damping force is purposely drawn larger than the side ones. In Fig. 4(2A), complete joint penetration has been reached, and the bottom changed from solid to liquid. The pool is now free to move either up and down, and the damping from the bottom becomes weaker. Because of this, the bottom damping force may be considered insignificant when the backside width/diameter of the weld pool becomes comparable with that on the front side, i.e., when the complete penetration state becomes significant. As such, for illustration purposes, it is eliminated in Fig. 4(2A). With the removal of the bottom damping force, it is expected that the decay of the oscillation will be much reduced such that the residual oscillation remains much stronger during the imaging time. The brightness of the reflected laser dots would reduce.

Figure 4(1B) and (2B) illustrates the decay of the oscillation. When in partial penetration, because the damping force is strong (Fig. 4(1A)), the motion, in all directions, is literally obstructed. However, after complete joint penetration is achieved, the damping in the axial direction was reduced - Fig. 4(2A). The motion in the axial direction was less obstructed. Thus, as shown in the waveform (Fig. $4(1 \mathrm{~B})$ ), the negative half cycles were very small compared to the upward cycle. It does not completely disappear because the pool is liquid and can expand laterally to aid the downward movement. This can be seen from the dotted curve in Fig. 4(1A), which indicates the motion of the surface toward the downward direction. In addition to affecting the shape of the oscillation waveform, the strong bottom damping force also affected the amplitude and frequency of the waveform. The pool surface could only reach limited height before it moved down, which was even more limited. Because the surface was confined in the vertical motion, it had to bounce up and down at a higher speed than when it had more free surfaces, as in the case of complete joint penetration - Fig. 4(2A). This corresponds to higher frequency in oscillation. Figure 4(1B) and (2B) depicts the difference. All

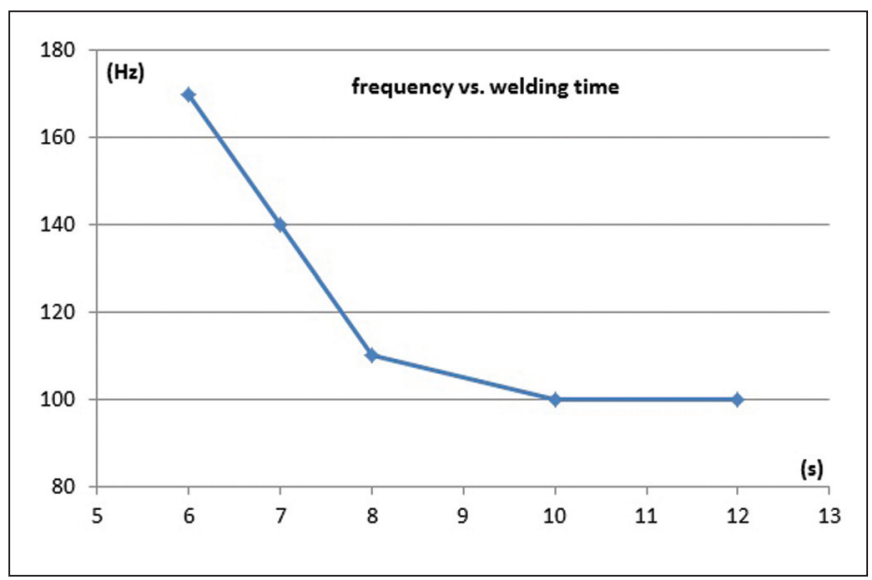

Fig. 5 - 150/20 A (22/3 ms) pulsed GTA on $1 / 8$-in. 304 stainless steel flat bar, weld pool oscillation frequency vs. welding time. 
this is both intuitively comprehensible and is confirmed indirectly by experiment results.

Figure 5 shows the frequency change vs. welding time from five experiments, which have the same conditions except for the welding time. Since the oscillation frequency cannot be measured directly, it is constructed by taking all the pictures during welding and finding the elapsed time that the same pattern appears periodically. The time found is the period, and the inverse of it (frequency) is used for the plot (Ref. 35).

\section{The Effect of Weld Pool Oscillation on Dot Matrix Images}

In this study, image capturing was conducted right after the current was switched from the peak to the base level, and the time for capturing the images was much shorter than the welding time (the peak current time). Because the oscillation period was much longer than the imaging time, the image acquired actually sampled the change of the weld pool surface in a fraction of the oscillation period. Both the oscillation amplitude and frequency affected the change the weld pool surface experienced in the imaging time. A larger amplitude and higher frequency both tend to increase the change the weld pool surface experiences within the imaging time. Since the oscillation frequency in partial penetration was greater than that in complete penetration, it would be unclear how the change in the weld pool surface (as measured by brightness of the image of the reflected dots) would compare in two penetration states. If the image becomes fuzzier after complete joint penetration is established, it must be concluded that the amplitude of the residual oscillation in complete penetration is much stronger than that in partial penetration.

\section{The Convex Weld Pool Surface}

Figure 6 depicts the spread of an imaged laser dot when the pool is oscillating. When the change in the weld pool surface due to the oscillation during the imaging time is small (which is indicated by the small variation in the pool surface in Fig. 6(1A)), the original dot is imaged to a dot with a slightly larger area on the imaging plane. When the change in the weld pool surface due to the oscillation during the imaging time is significantly increased as shown in Fig. $6(2 \mathrm{~A})$, the imaged dot has a much wider area. The oscillation of the weld pool thus makes the imaged dot less bright, and the scale of the change in the weld pool surface during the imaging time determines the brightness of the reflected laser dots.

In optics, Lumen describes the luminous power a light source can produce in unit time. Since the same laser is used for all imaging in this study, Lumen $\left(\varnothing_{v}\right)$ is a fixed quantity. Luminous energy $\left(Q_{v}\right)$ is a product of Lumen and time, and in this case, is the exposure time (Ref. 36):

$$
Q_{v}=\varnothing_{v} \times t
$$

Because exposure time (imaging time) is fixed in this study ( $1 \mathrm{~ms}), Q_{v}$ is a fixed quantity too. Illuminance is the
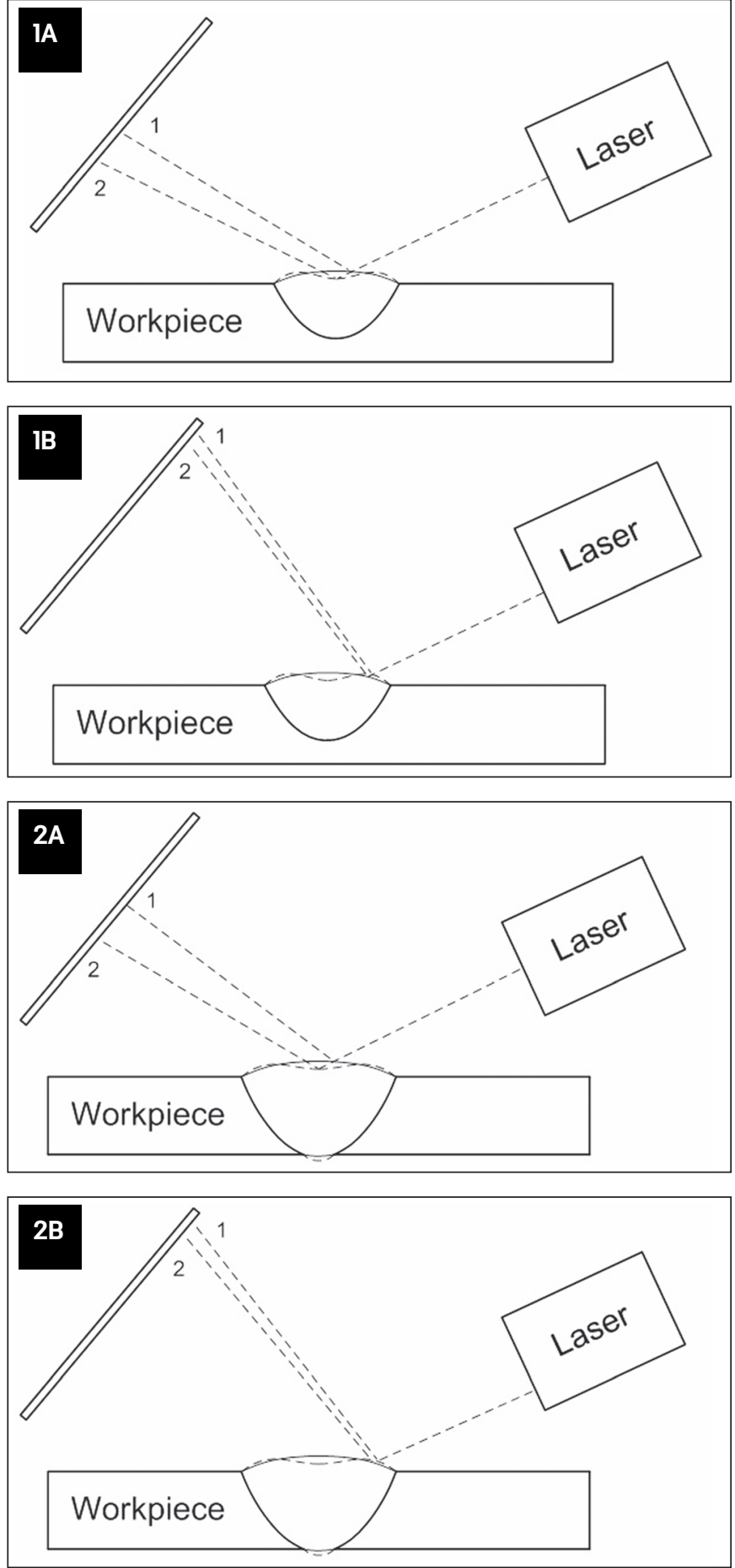

Fig. 6 - The effect of the pool oscillation on the imaging of a laser dot: $1 A-$ Middle pool area reflection in partial penetration; $2 A-$ middle pool area reflection in critical penetration; $\mathrm{lB}-$ edge pool area reflection in partial penetration; $2 \mathrm{~B}-$ edge pool area reflection in critical penetration.

luminous power incident on a surface of unit area, i.e.,

$$
E_{v}=\varnothing_{v} / S
$$

where $S$ is the area of the illuminated surface.

When you rewrite Equation 3 as $\varnothing_{\mathrm{v}}=\mathrm{E}_{\mathrm{v}} \times \mathrm{S}$ and substi- 


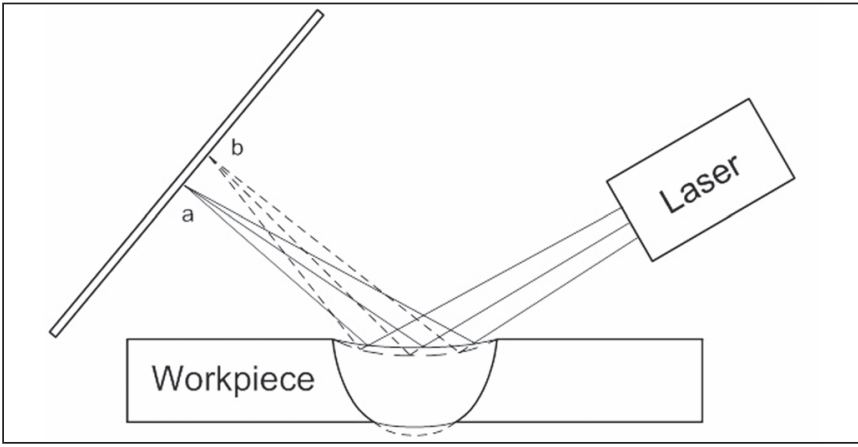

Fig. 7 - The effect of concave pool surface and pool oscillation on the imaging of the laser dots.

tute it into Equation 2, the following equation is derived:

$$
Q_{v}=E_{v} \times S \times t
$$

Since both $Q_{v}$ and $t$ are fixed, when the illuminated area $S$ is increased, illuminance $\left(E_{v}\right)$ decreases. Illuminance is the quantity that gives the impression of dimness or brightness depending on its values.

When the change in the weld pool surface due to oscillation with the given imaging time period increases, the same amount of luminous energy has to cover a wider area. Correspondingly, the illuminance will decrease from Equation 4, which leads to less brightness of the image.

The edge of the pool is not affected as much by the oscillation as the center area - Fig. 6(1B, 2B). However, the edge of the pool is not fixed either, and thus we can still see the difference in the spread of the images.

As can be seen, analysis suggests the change in the weld pool surface during the imaging time period will affect the clearness and the brightness of the images. Experiment results will further prove such theoretical analysis. After that, the next step is to find a correlation between the brightness (grayness) of the images and the pool oscillation stages, which determine the change in the weld pool surface during the imaging time period. This is an important step because the grayness calculation is faster than oscillation frequencies and makes it possible for online monitoring of the welding process.

\section{The Concave Weld Pool Surface}

When the pool surface is concave, as shown in Fig. 7, different reflection rays can converge, forming one imaged dot on the imaging plane. This makes the dot very bright since the lumen is multiplied by these light rays:

$$
E_{v}=n \times \varnothing_{v} / S
$$

where $n$ is the number of light rays, and $S$ is the illuminated area that a single ray hits.

When the pool oscillation is taken into consideration, the area swept through by the light rays increases as in the concave surface case. However, the increase in the area is likely not as significant as the number of light rays converged.
Let's assume the area now is $\mathrm{m} \times \mathrm{S}$, where $S$ has the same meaning as in Equation 5. The illuminance now becomes

$$
E_{v}=\left(\frac{n}{m}\right) \times \varnothing_{v} / S
$$

When the effect of the convergence is larger than that of the oscillation, $(n / m)>1$, we still see the imaged dot becomes brighter than the dot reflected by a single light ray. In addition, the dot is also large due to the pool oscillation. If the concave pool surface can be observed, we expect to see this phenomenon.

\section{Experimental Results and Discussion}

Two sets of experiments were conducted. In the first set, the welding current was fixed at $80 / 20 \mathrm{~A}$, but the welding time varied from 1 to $3 \mathrm{~s}$ with $1 \mathrm{~s}$ incremental steps. In the second set, the welding time was fixed at $3 \mathrm{~s}$, but the welding current varied from 30/20 A to 120/20 A with 10-A incremental steps in the peak current. The first set of experiments was designed to study the effect of the welding time, while the second was to study the effect of the welding current.

Since the raw data collected were the reflected dot images during the welding process, the method employed in this study was 2D. By studying the 2D image data, much more information could be revealed as we see in the following results.

\section{The Effect of Welding Time on the Weld Pool Penetration}

In Fig. 8, a common pattern observed is that in the early stage of welding, only a few (one or two) laser dots are imaged, and the number increases steadily. It was also observed that in the early stage, the dots are generally clear and bright. As time progresses in the 2- and 3-s welding, the center dots are distorted more than the edge dots, they become fuzzier, and their brightness decreases. As time progresses even further as shown in the 3-s welding, a very large and bright dot may form if the oscillating weld pool surface is concave during the imaging, but the surrounding dots become few and very dim. However, the weld pool surface may also be convex during the overpenetration state depending on the phase of the oscillation during the imaging time such that the image would be similar as in moderate complete penetration.

The finished weld surfaces shown in Fig. 9 show that in the 1-s welding, complete joint penetration is not reached as the bead is only barely visible on the backside. Moderate complete penetration is reached in the 2-s welding. In the 3-s welding, the weld pool may be considered overpenetrated as can be seen from the overly large bead on the backside.

As we have seen in a lot of repeated experiments, the pattern observed is well correlated with the penetration stages, i.e., before complete joint penetration, the dots are less in number but bright and clear; when moderate complete penetration is reached, the dots are distorted, become fuzzier, 

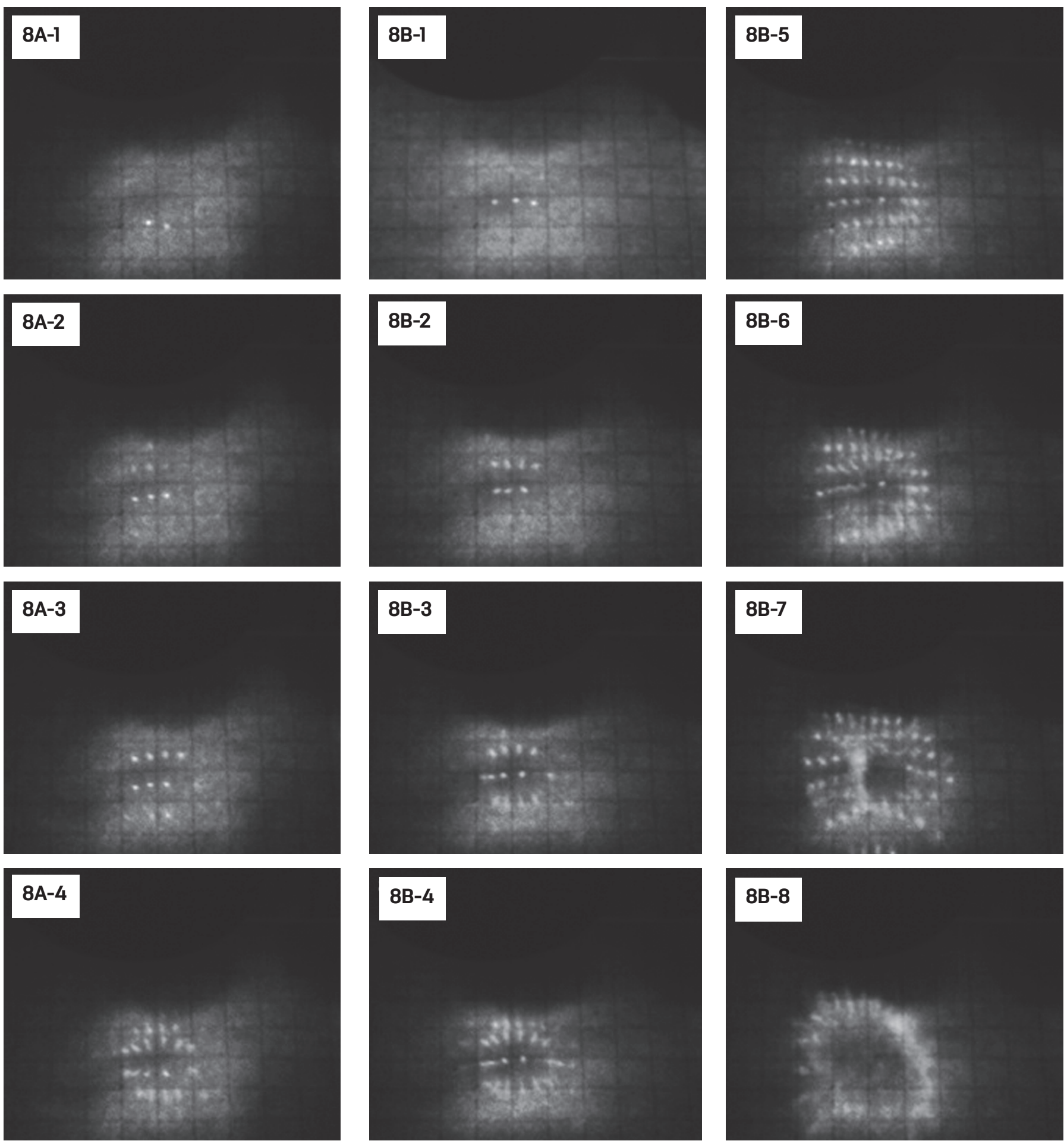

Fig. 8 - Captured images displaying the evolution of weld pool penetration in the first set of experiments: A - 1-s welding; B 2-s welding; $\mathrm{C}-3-\mathrm{s}$ welding.

and their brightness starts to decrease; when the pool is overpenetrated, an overly large and very bright dot can form. Later experiments also show that with overpenetration, the overall imaged dots can also be very dim depending on the phase of the oscillation during the imaging time. However, for moderate complete penetration, the weld pool surface is always convex.
This correlation indicates the grayness information can be utilized to distinguish between partial and moderate complete penetration. (Overpenetration can be temporarily ignored because we will control the process for moderate complete penetration such that the weld pool is not allowed to develop into an overly penetrated state.) Since acquiring the grayness value of image pixels is easy and fast, as can be 

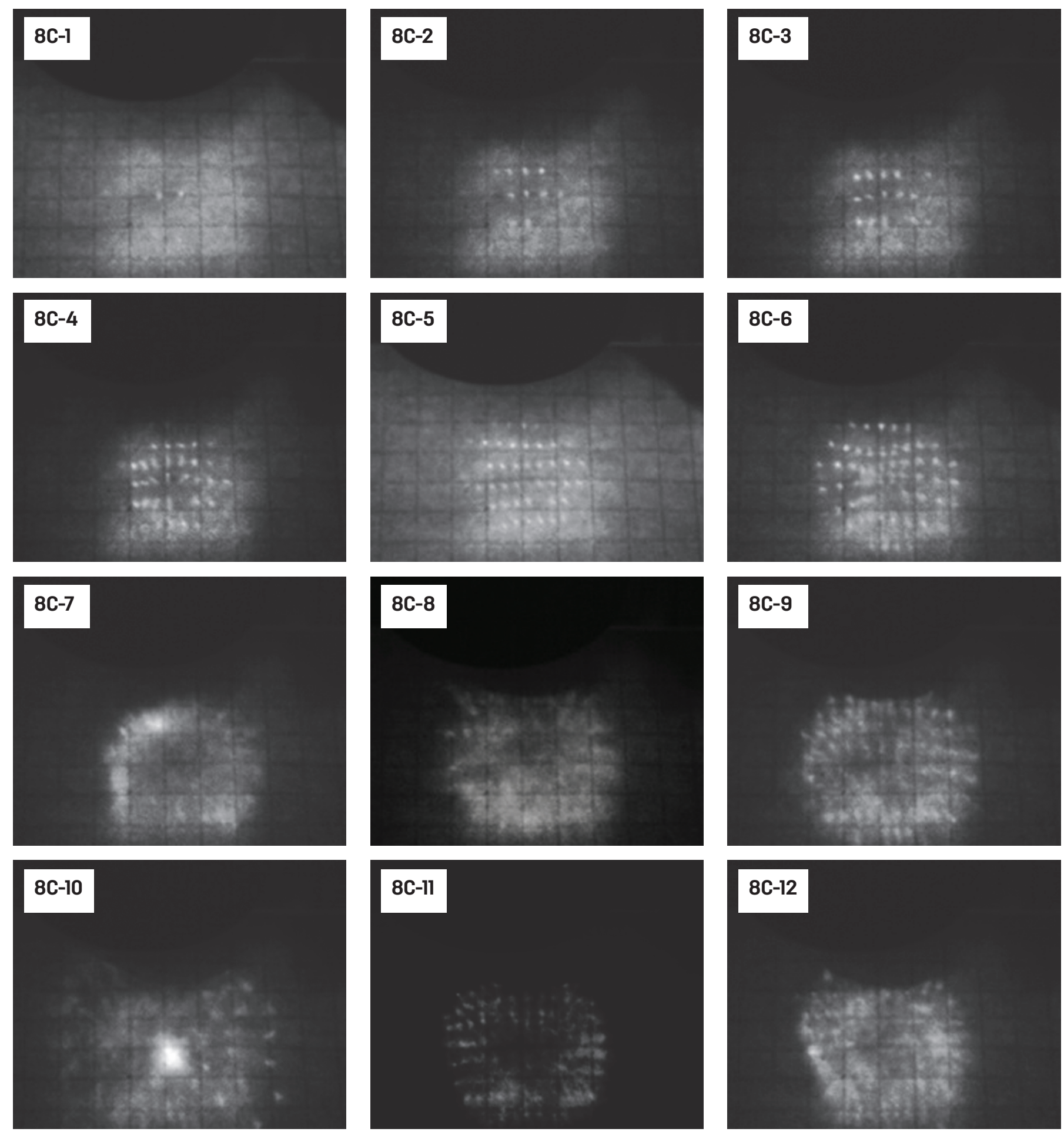

Continuation of Fig. 8.

seen in Fig. 10, this makes online control of the weld pool penetration possible. Figure 10 shows the identification of the grayness values of pixels using Matlab's image tool. The brightness on the numbers indicates the brightness of the pixels. Although the figures show a manual process, it may well be automated by a computer program, which is done in this study.

The next step is to decide on how to use the grayness val- ues of the pixels to characterize the weld pool evolution from partial to moderate complete penetration. Three calculation methods were carried out. In the first one, only the grayness value of the brightest pixel was used to represent the grayness of the image captured at that instant. In the second one, the average grayness value of the first 20 brightest pixels was used to quantify the brightness of the captured image. In the third experiment, the average of the first 

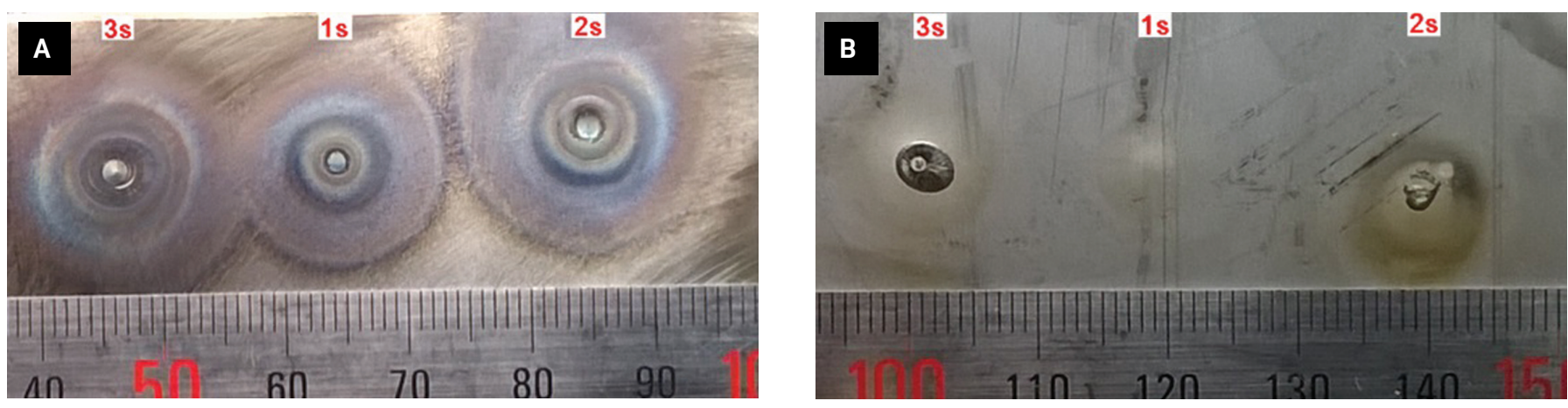

Fig. 9-The surface morphology of the finished welds in the first set of experiments: A - Front view; B - back view.
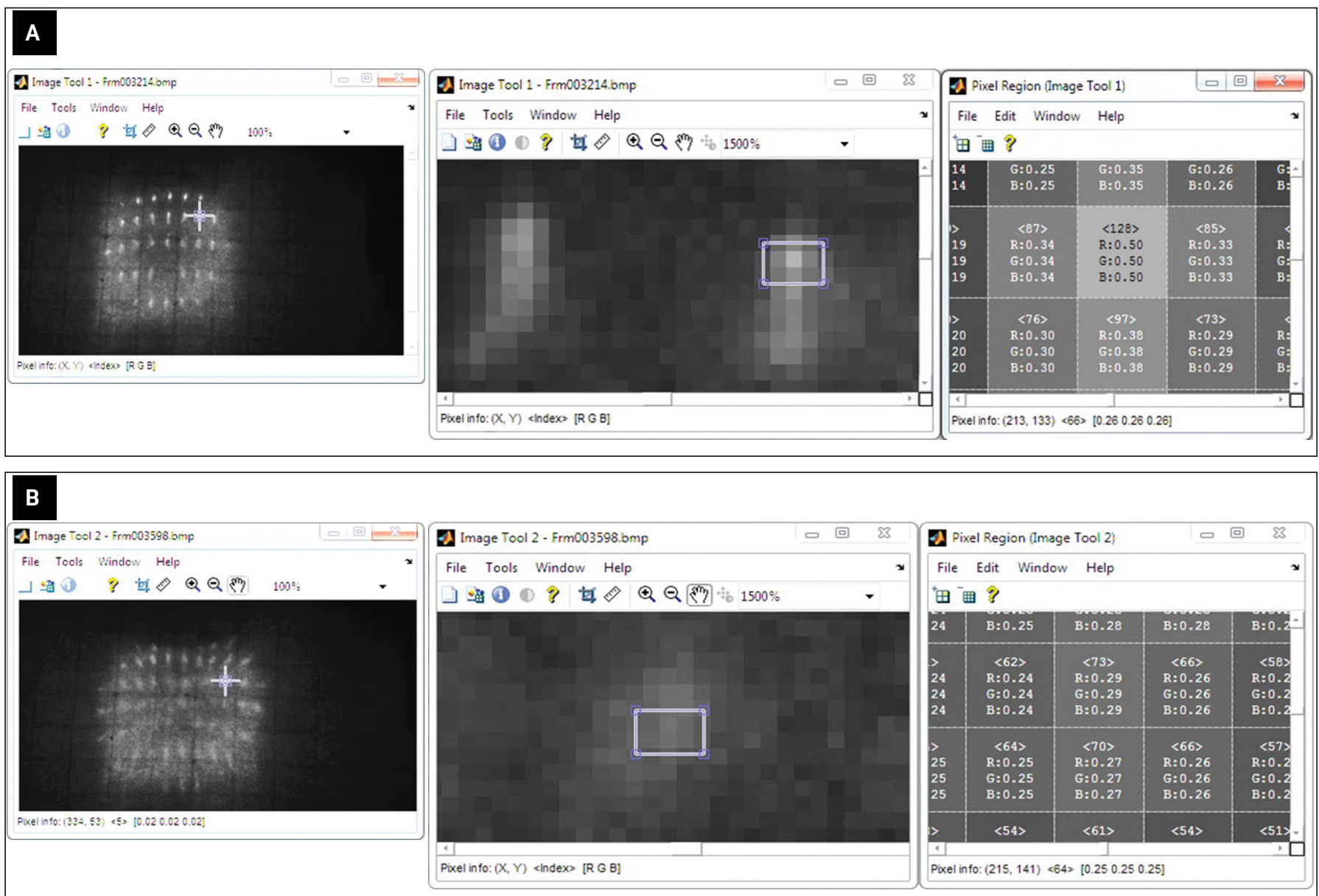

Fig. 10 - Reflected dot images and their individual pixel's grayness value: A - Partial penetration; B - critical penetration.

100 brightest pixels was used. This was done for all the pictures captured that represent the entire welding process, and they were plotted as a function of the welding time. Results showed that, in the first case, the variation of the brightness was too dramatic and did not reflect the observed pattern well. This is because one pixel's grayness value could not really represent the overall brightness of the image in our impression. That selected pixel may very well be an outlier. When the grayness values of the first 100 brightest pixels were averaged, the variation of the grayness with time leveled down. The key stages of the weld pool pen- etration could not be easily identified from the plotted curve. It is expected that with more pixels used for averaging, the leveling down of the variation will continue until the curve approaches a horizontal line. Besides, using more pixels for averaging increased the calculation time and made it less preferred for online control. By comparison, use of the first 20 brightest pixels for averaging is the best of the three methods. As such, the 20-pixel averaging method was used for studying the evolution of the weld pool penetration, and the results are shown in Fig. 11.

From Fig. 11, it can be seen that when the weld pool is 

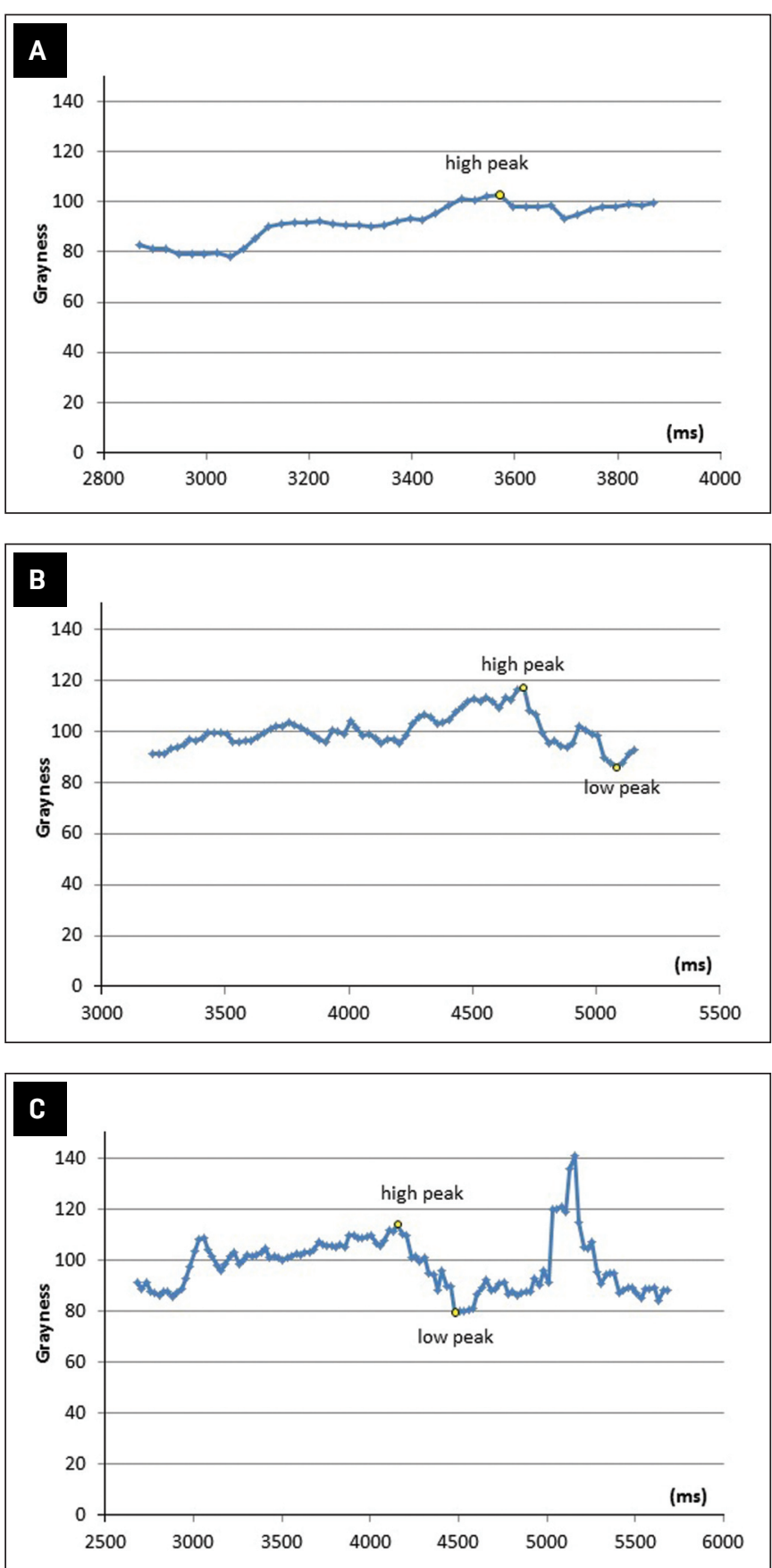

Fig. 11 - Grayness variations with welding time for the three welding times: $A-1-s$ welding; $B-2-s$ welding; $C-3-s$ welding.

just formed, the average grayness is low in all three welding conditions. This is due to the few imaged dots that are formed. Although they are bright, their number is small and thus the overall brightness of the images is low. As time progressed, the number of imaged dots increased dramatically, and correspondingly the grayness jumped to high values in a short time. When the grayness reached its first peak, it started to decrease. This can be explained from the dimness of the imaged dots in Fig. $8 \mathrm{~B}$ and C. Imaged dots start to become dim starting at the seventh pictures in both B and C. This state is not reached in Fig. 8A since the welding time is too short to reach complete penetration. In Fig. 8C, a very big and bright dot is formed after the dimness, followed by further dimness. This is shown in the grayness plot as a second peak with a very high value and the subsequent sudden drop. The formation of the big and bright spot has been discussed.

By correlating the image grayness and the weld pool penetration, the important location on the grayness plot is found, which indicates the advent of complete joint penetration, and it is near the first peak. When complete joint penetration was reached, the grayness decreased somewhat. Experiments showed that when the pool was completely penetrated, the decrease in grayness was about 20 to $30 \%$ of the peak value. This behavior of the image grayness variation was consistently observed, which makes it possible for online control of the weld pool penetration. Utilizing this finding in the welding process control system is a topic in the follow-up research.

Although small peaks are sometimes observed before the first large peak that is identified as the key region to indicate critical penetration, those peaks do not differ from their closest lower location by at least $20 \%$, and are thus not considered as the critical penetration indicator. Due to the variation in the welding process, small variations of the grayness that lead to the small peaks are unavoidable, but are considered as noises.

\section{The Effect of the Welding Current on the Weld Pool Penetration}

In the second set of the experiments, the welding time was fixed, but the peak welding current was varied. As pointed out earlier, the captured images depicting the weld pool evolution process are similar to those in Fig. 7 and will not be repeated. Since the grayness variation with welding time is of interest, they are shown in Fig. 12.

When the peak current was only $30 \mathrm{~A}$, as shown in Fig. $12 \mathrm{~A}$, the first peak was never observed during the entire welding time. The grayness continued to increase but only slowly. This indicated that complete penetration never occurs in this case. It is possible that given enough time, complete joint penetration will eventually appear. However, if the heat absorbed by the workpiece from the welding torch is equivalent to the heat dissipated, the weld pool may not grow large enough to reach complete penetration. Thus, a current of 30 A may not be able to establish the complete penetration to observe the first peak in the grayness.

As the peak current is increased to $40 \mathrm{~A}$ (Fig. 12B), the first grayness peak occured with a value of 155 at the welding time of $10 \mathrm{~s}$. With subsequent increases in peak current, the first grayness peaks were more pronounced - Fig. 12C to $\mathrm{H}$.

When the peak current reached $120 \mathrm{~A}$, the first peak did not occur. A separate experiment has shown that under such high peak current, complete joint penetration occurs at about $2.5 \mathrm{~s}$. However, from Fig. 12J, there is no observable peak at $2.5 \mathrm{~s}$. This occurs probably because the development from moderate complete penetration to overpenetration was too quick. Since it is hard to identify the first peak at this current, the grayness evolution cannot be used for further dynamic control of the welding process. 


\section{WELDING RESEARCH}
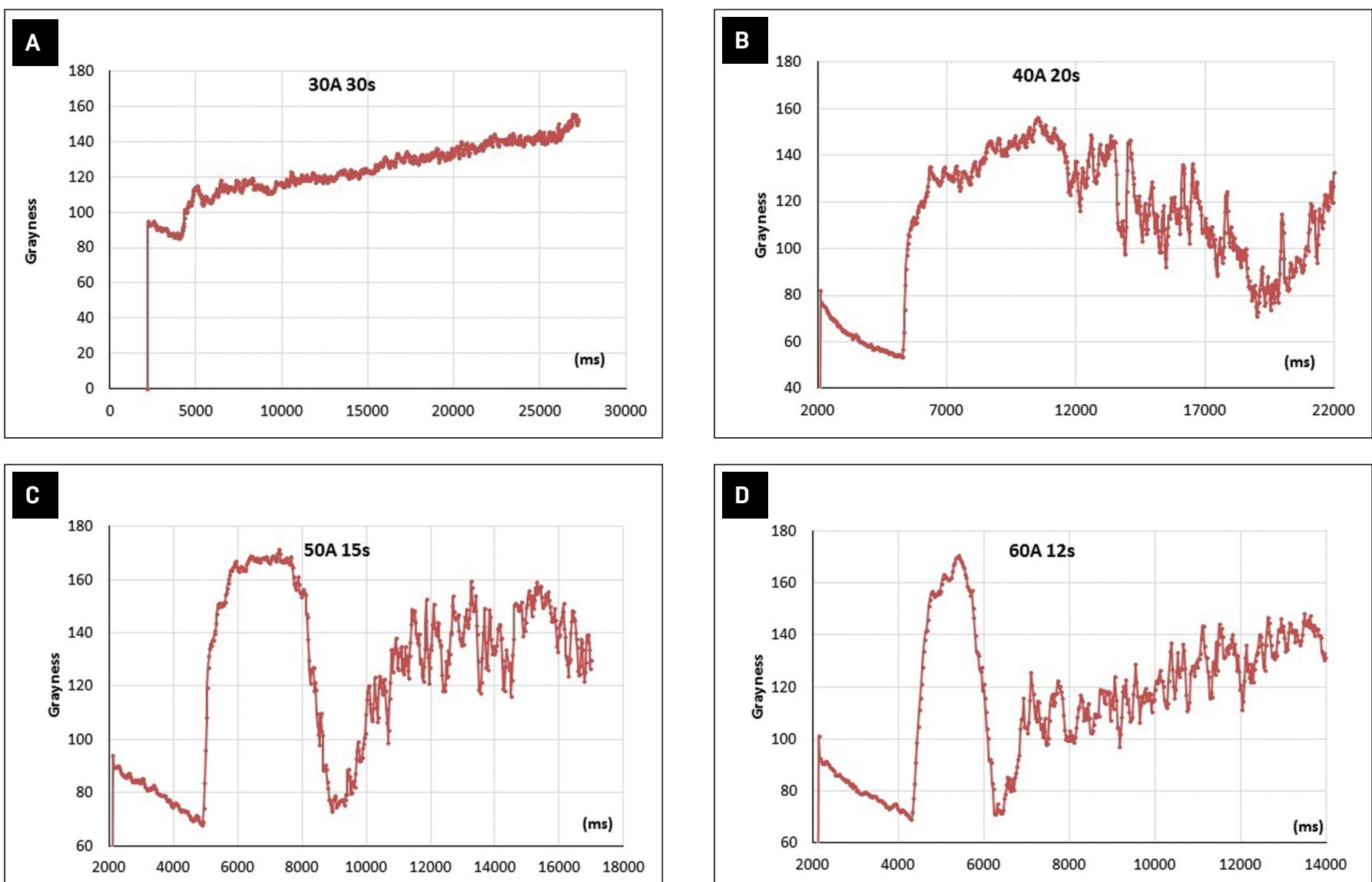

D
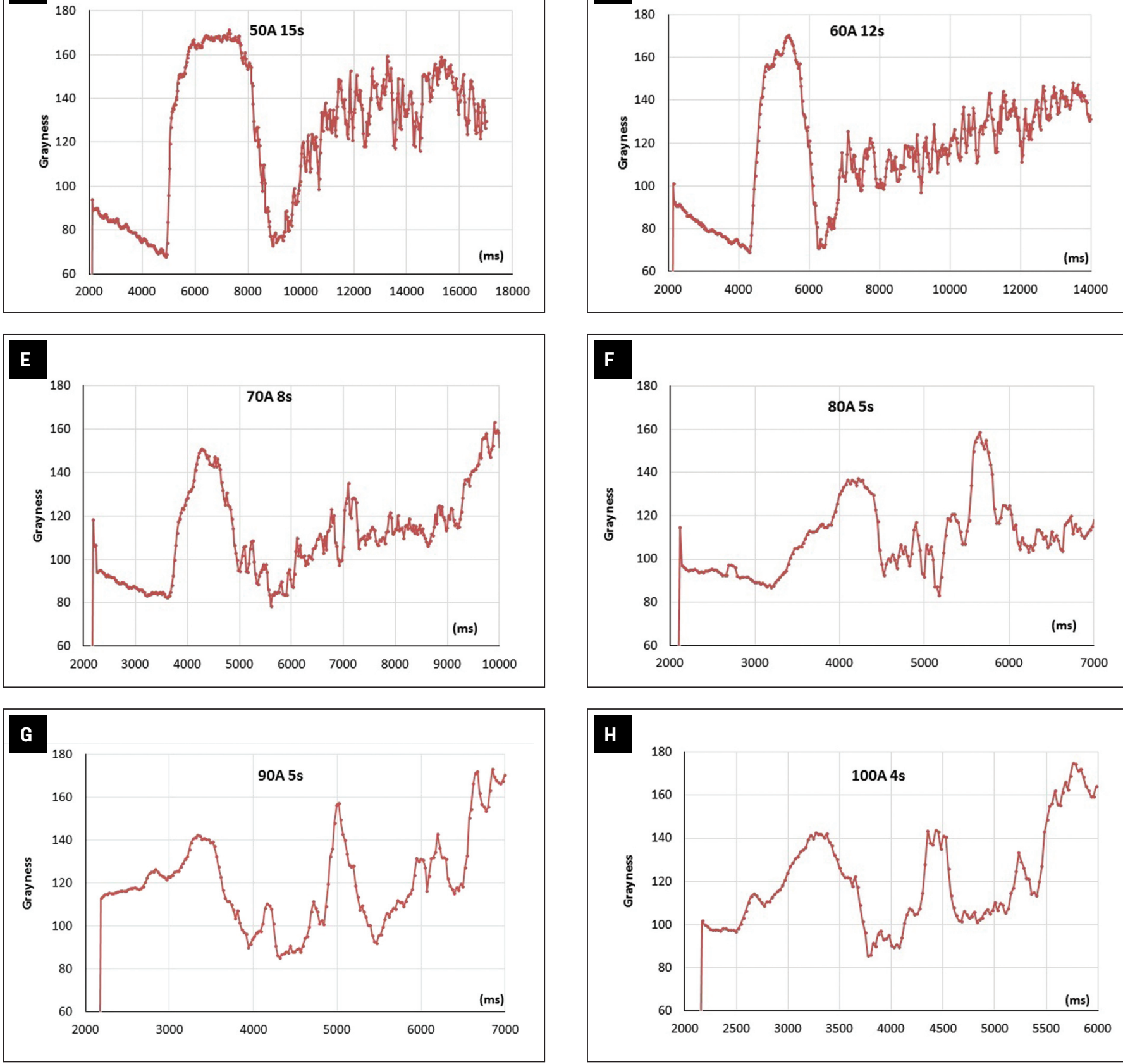

H

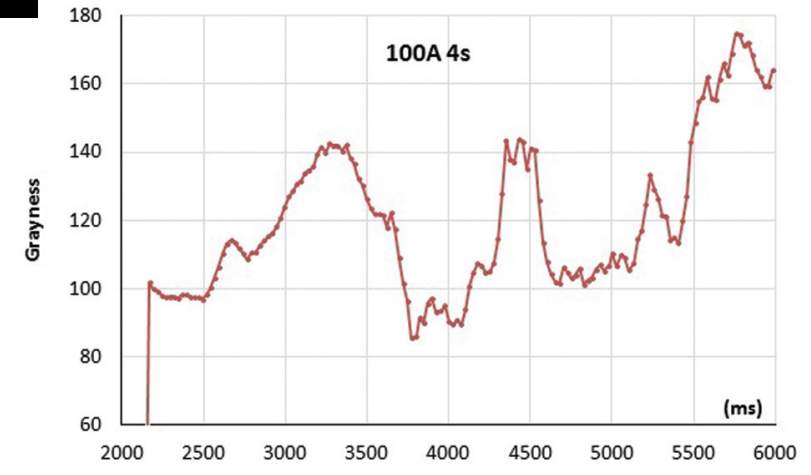



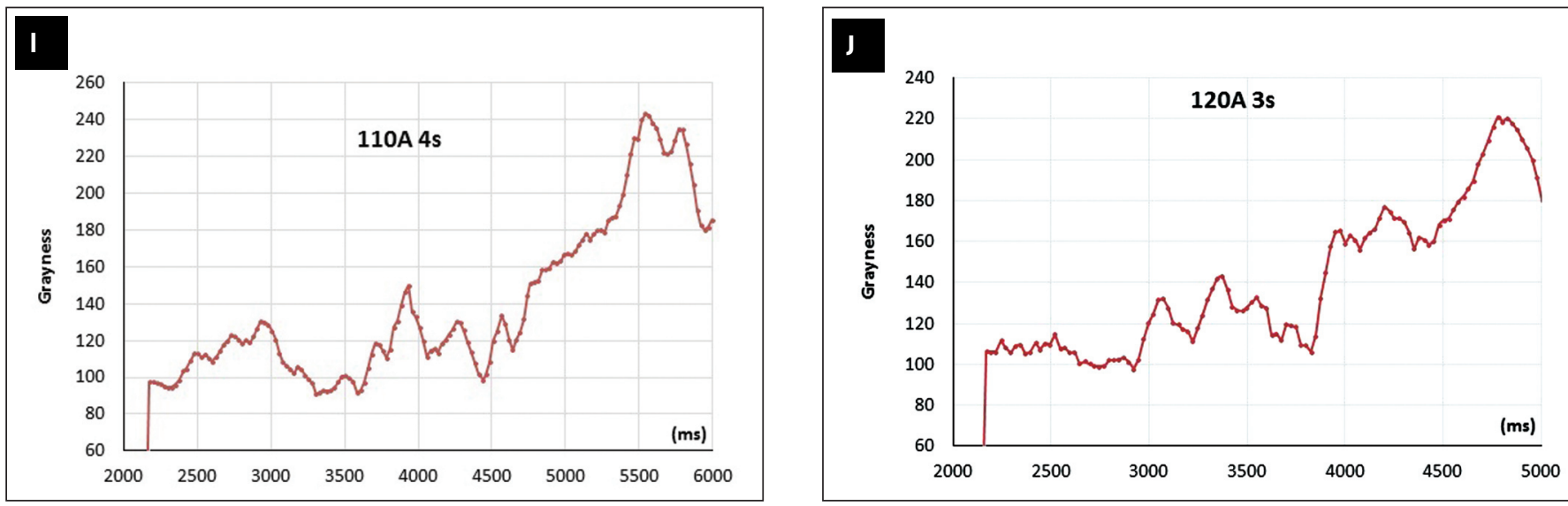

Fig. 12 - The effect of the different peak welding current on the image grayness evolution: $A-P e a k$ current $=30$; $B-$ peak current $=40 \mathrm{~A} ; \mathrm{C}$ - peak current $=50 \mathrm{~A} ; \mathrm{D}$ - peak current $=60 \mathrm{~A} ; \mathrm{E}-$ peak current $=70 \mathrm{~A} ; \mathrm{F}-$ peak current $=80 \mathrm{~A} ; \mathrm{G}-$ peak current $=90 \mathrm{~A} ; \mathrm{H}$ - peak current $=100 \mathrm{~A} ; \mathrm{I}$ - peak current $=110 \mathrm{~A} ; \mathrm{J}$ - peak current $=120 \mathrm{~A}$.
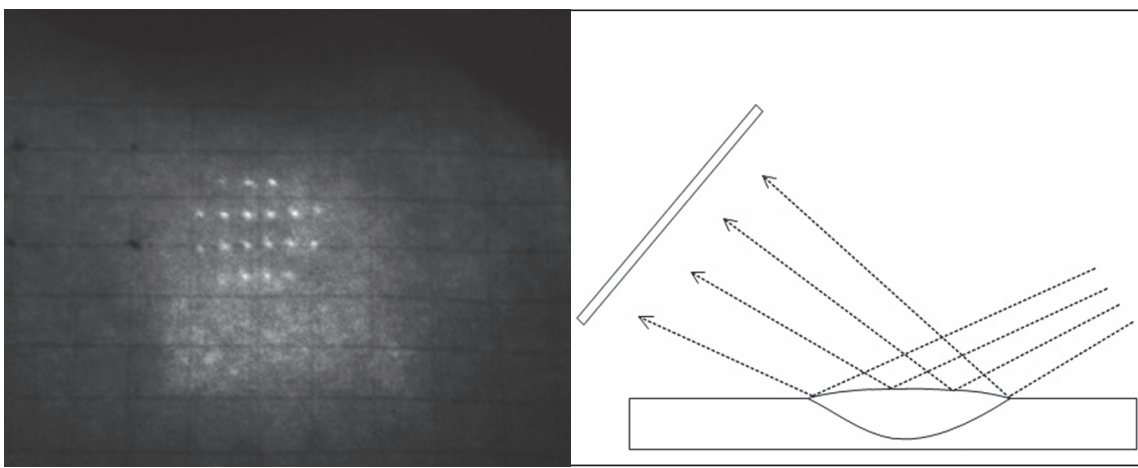

Fig. 13 - Stable reflection
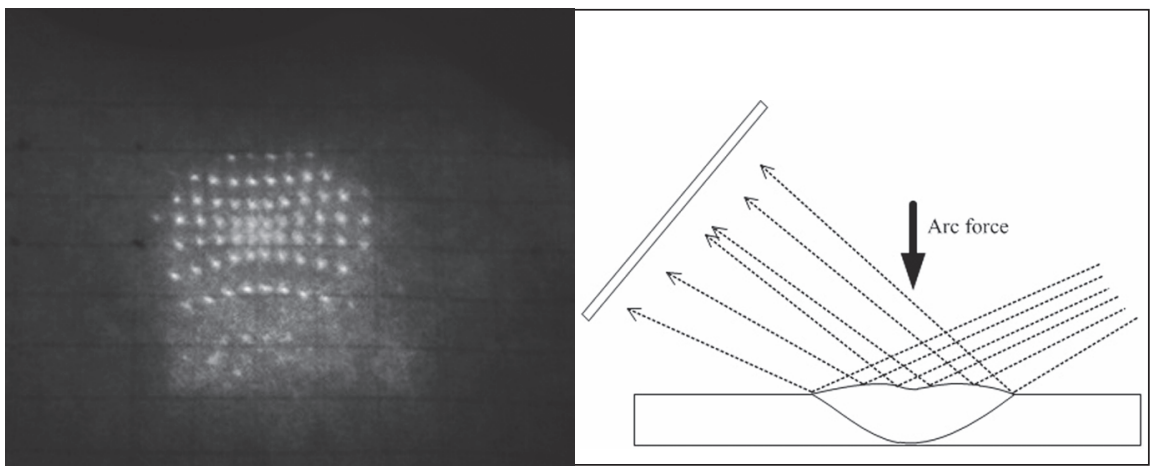

Fig. 14 - Oscillated reflection: Image due to reflection on concave surface location. mune to noise as compared to other methods discussed previously since the method works in a wide-peak welding current range.

The base current period also affected the grayness pattern. This is because the used camera can take only one picture per ms. This basically sets the lower end of the base current period, which is $3 \mathrm{~ms}$. This is because during the 3-ms period, three pictures can be taken. However, when the first picture was taken, instruction from the PC had just been sent to lower the power supply. During this period, the current may still be high. As is well known, high arc radiation interferes with imaging. On the other hand, when the third picture is being taken, instructions are also sent to increase the current. During this time, the arc radiation can become strong, and thus could affect the picture taken.

Generally speaking, longer base period time does not adversely affect imaging. However, setting a too long base period makes welding too slow, which is not efficient. Overall, the base current period cannot be lower than $3 \mathrm{~ms}$, but can be as long as desired.
From the results, it can be seen that the image grayness is significantly affected by the welding current. With too low or too high welding current, the normally observed peak pattern disappears. Thus, in order to use the image grayness variation to control the welding process, the range of peak current has to be limited to between 40 and $110 \mathrm{~A}$.

Although there is a range in the peak welding current where the desired pattern can be observed, in comparison to other methods (Refs. 12-15), the range is much wider. This means the method developed in this study is more im-

\section{Additional Analysis and Discussion}

As is shown in Fig. 7, during welding, the images can become distorted. In some cases, many imaged dots can be crowded in a small area, while in other cases, a few dots are scattered in a larger space. These phenomena as well as the normal imaging can be explained from the following optical schematics: 


\section{Smooth and Relatively Flat Pool Surface}

In this early stage of welding, since the weld pool is small and its backside is not melted, the weld pool surface is relatively stable. The pool oscillation has a high frequency, but small amplitude. The small amplitude is not enough to change the weld pool surface significantly during the imaging time period to make the light ray scatter much; subsequently, the reflected image is both stable and clear. It shows in Fig. 13.

\section{Irregular Pool Surface Due to Strong Oscillation}

When the pool is close to complete joint penetration, the oscillation amplitude is large, but its frequency is low. The oscillation can cause local bumps or valleys on the pool surface. Correspondingly, certain patterns were observed. Due to the effect of the local irregularities on imaging, the overall picture was distorted and individual dots displayed certain degrees of dimness. The grayness of the dots was also reduced.

In this case, the valley on the pool surface caused some light rays to converge. Although the reflected dots were not combined to form a bigger one, this effect did make the dots move closer to each other. Thus, as can be seen from the picture in Fig. 14, the middle part of the picture is distorted.

When a local area displays certain convexity as shown in the right plot of Fig. 15, it will scatter the light rays incident on it, and cause the reflected image dots to move away from each other. This can be seen in the right picture in Fig. 15.

\section{Behaviors in Butt Joint Welding}

It should be mentioned that this paper is mostly concerned with, and conducted for, the weld pool behaviors and their underlying mechanisms in the ideal welding conditions, i.e., there are no gaps or distortions at the joints. In reality, these conditions are most likely not satisfied. For example, the gaps between two workpieces always exist, although in some cases the butting edges of the two workpieces are so smooth and they fit into each other so well that the gaps are not obviously visible. In such nonideal conditions, the method in determining when complete joint penetration is reached may need to be modified to a certain degree.

Figure 16 compares the weld pool characteristics and the reflected images from ideal and nonideal joints in early welding process (early partial joint penetration). In the ideal case (1A, 1B), the weld pool forms a convex surface and, correspondingly, a few clear dot matrix images are formed. In the nonideal case (2A, 2B), since there is a gap, the weld pool does not have much support at the bottom, and it sags and forms a concave top surface. This leads to the formation of one large and fairly bright dot image. If the previously established method in the paper is used to determine complete joint penetration, it could falsely identify partial as complete joint penetration.

To detect complete joint penetration in nonideal butt joint welding, a separate method was developed. In this method, a threshold value of the dot area (grayness area) was first identified experimentally. Generally, for a larger welding current, the value was larger. For the subsequent welding process, the area of the large bright image dot was calculated and com- 


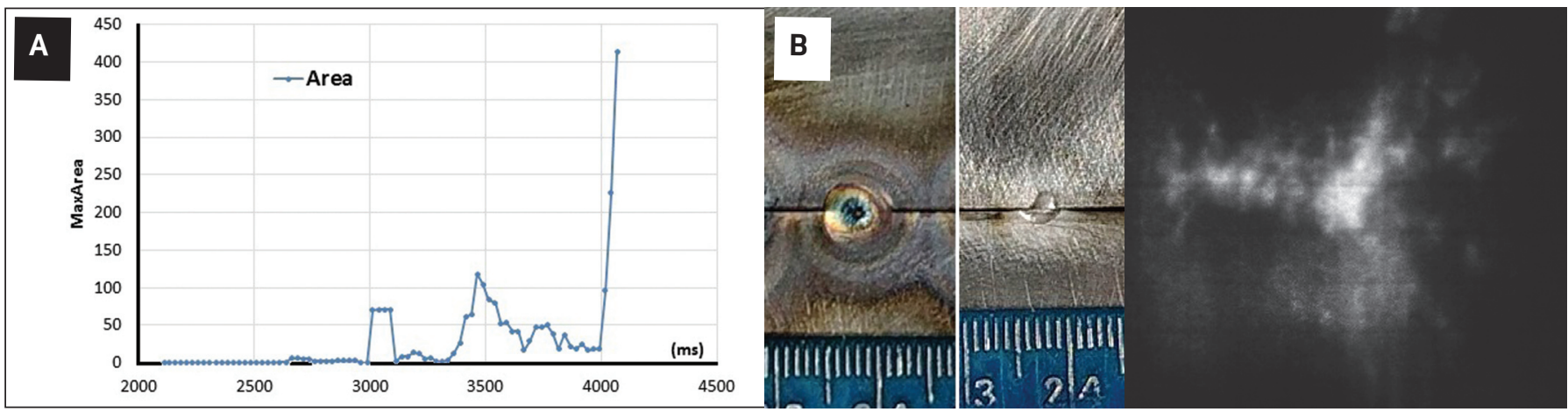

Fig. 17 - Experiment results of nonideal butt joint welding with I = 120 A: A - Plot of area of the largest image dot vs. time; $B-$ front, back surface of the weld and the largest image dot.

pared in real time with the threshold. When it reached the threshold, complete joint penetration was reached and welding on that spot was accomplished. Preliminary results showed this method was effective in the nonideal butt joint welding. Figure 17 shows the experiment results.

With a welding current of $120 \mathrm{~A}$, the threshold of the grayness area was experimentally determined to be 300 pixels. After identification of the threshold, to evaluate the effectiveness of the method, a welding process was started and the grayness of the largest dot was calculated in real time. As the dot grew and reached the threshold, the welding process was terminated. Both front and back surfaces were captured. As we can see from the backside surface in Fig. 17B, complete joint penetration is reached. More experiments are under way to improve this method.

\section{Conclusion}

This paper aims to develop a novel, real-time weld penetration monitoring method based on the weld pool oscillation. While previous studies primarily focused on the correlation between the oscillation frequency and weld joint penetration, and detected the penetration based on the measured oscillation frequency, this study aimed at a method that does not actually measure the frequency of the weld pool oscillation. Through studying how the image of the laser dots reflected from the specular weld pool surface in pulsed GTAW changes with the dynamic behaviors of a developing weld pool, it was found that the image of the reflected laser dots became less clear and dimmer as the weld penetration increased. As such, the brightness of the reflected laser dots can be used to detect the weld penetration.

Through the substitution of the brightness of the image of the reflected laser dots for the frequency of the weld pool oscillation, the weld penetration can be determined by comparing the brightness with its history. The detection for the weld penetration thus becomes real time. However, in previous methods that are based on the oscillation frequency, when the penetration needs to be determined, a time period must be added to obtain signals to calculate the frequency. A delay is thus introduced in the weld penetration detection. It is apparent that the use of the 2D signal (image used to compute the brightness) solved the real-time detection issue by increasing the dimension in the signal to remove the need for the time in the signal.
In previous methods that are based on the oscillation frequency, to maximize the signal to noise ratio to accurately calculate the pool oscillation, an interruptive pulse in the current was applied to excite the weld pool to oscillate. If current pulses are repeatedly applied, i.e., if the process is pulsed GTAW, the weld pool oscillation will be a forced oscillation, which is much more complex, and a derivation of the resonant oscillation frequency the previous methods rely on will be challenging. Hence, the previous methods have challenges to be applied in pulsed GTAW, which is widely used. Further more, adding a pulse to excite the pool oscillation allows the previous methods to improve the signal to noise ratio, but it introduces an interruption to the welding process. The proposed method aimed for the widely used pulsed GTAW and introduced no interruptions.

The brightness of the image of the reflected laser dots was determined by the range scanned by the reflected laser dots during the period the image sensor integrated the optical signal. Since the time for the integration of the optical signal on the image sensor ( $1 \mathrm{~ms}$ in this study) was much smaller than the oscillation period, the scan of the reflected laser dots was due to the change of the reflection surface (weld pool surface) within an oscillation cycle. Since the oscillation frequency, although changes with the penetration, did not change drastically, it is arguable that the effect of the scan on the brightness was primarily determined by the change speed of the weld pool surface. Hence, the proposed method may be considered to be more based on the surface change than on the oscillation frequency. On the other hand, the surface change speed directly determined the clearness of the reflection image without the need for a full oscillation period. From this point of view, this work presented a milestone result in the development of weld pool oscillation-based weld penetration detection through its mechanism to permit a faster detection speed.

The oscillation on which the proposed method is based is a forced oscillation generated by the repeatedly applied current pulses. While its frequency may be relatively complex, the amplitude has a simpler and more fundamental relationship with the penetration. Per analysis, the amplitude of the oscillation in the pulsed GTAW drastically changes with the weld penetration because the damping provided by a solid support and the surface tension is not comparable. As such, the proposed method is based on a more robust foundation that correlates the weld penetration to the detected signal. 


\section{Acknowledgments}

This work is partially funded by the Department of Energy under contract number DE-AC05-00OR22725, the National Science Foundation under grant IIS-1208420, and the China Scholarship Council.

\section{References}

1. Connor, L. P., and O’Brien, R. L. 1991. Welding Handbook: Welding Processes. American Welding Society.

2. Hartman, D. A. 2010. Assessing penetration during fusion welding: A survey of techniques. Manufacturing Behavioral Science.

3. Kotecki, D. J., Cheever, D. L., and Howden, D. G. 1972. Mechanism of ripple formation during weld solidification. Welding Journal 51(8): 386-s to 391-s.

4. Renwick, R. J., and Richardson, R. W. 1983. Experimental investigation of GTA weld pool oscillations. Welding Journal 62(2): 29-s to 35-s.

5. Zacksenhouse, M., and Hardt, D. E. 1983. Weld pool impedance identification for size measurement and control. Journal of Dynamic Systems, Measurement, and Control 105(3): 179-184. DOI: 10.1115/1.3140652

6. Xiao, Y. H., and den Ouden, G. 1990. A study of GTA weld pool oscillation. Welding Journal 69(8): 289-s to 293-s.

7. Xiao, Y. H., and den Ouden, G. 1993. Weld pool oscillation during GTA welding of mild steel. Welding Journal 72(8): 428-s to 434-s.

8. Aendenroomer, A. J. R., and den Ouden, G. 1998. Weld pool oscillation as a tool for penetration sensing during pulsed GTA welding. Welding Journal 77: 181-s to 187-s.

9. Hardt, D., and Katz, J. 1984. Ultrasonic measurement of weld penetration. Welding Journal 63(9): 273-s to 281-s.

10. Fenn, R. 1985. Ultrasonic monitoring and control during arc welding. Welding Journal 64(9): 18-s to 22-s.

11. Carlson, N. M., and Johnson, J. A. 1988. Ultrasonic sensing of weld pool penetration. Welding Journal 67(11): 239-s to 246-s.

12. Carlson, N. M., et al. 1992. Ultrasonic NDT methods for weld sensing. Materials Evaluation 50(11): 1338-1343.

13. Yang, J., et al. 1994. Ultrasonic weld penetration depth sensing with a laser phased array. Proceedings of 1994 ASME International Mechanical Engineering Congress, PED, Manufacturing Science and Engineering, Chicago, Ill., Nov. 6-11, 68: pp. 245-254.

14. Graham, G. M., and Ume, I. C. 1997. Automated system for laser ultrasonic sensing of weld penetration. Mechatronics 7(8): 711-721. DOI: 10.1016/S0957-4158(97)00031-7.

15. Mi, B., and Ume, C. 2006. Real-time weld penetration depth monitoring with laser ultrasonic sensing system. Journal of Manufacturing Science and Engineering 128(1): 280-286. DOI: 10.1115/ 1.2137747 .

16. Kita, A., and Ume, I. C. 2007. Measuring on-line and off-line noncontact ultrasound time of flight weld penetration depth. Weld ing Journal 86(1): 9-s to 17-s.

17. Nagarajan, S., Banerjee, P., Chen, W. H., and Chin, B. A. 1992. Control of the welding process using infrared sensors. IEEE Transactions on Robotics and Automation 8(1): 86-93. DOI: 10.1109/70.127242.

18. Nagarajan, S., Chen, W. H., and Chin, B. A. 1989. Infrared sensing for adaptive arc welding. Welding Journal 68(11): 462-s to 466-s.

19. Chen, W. H., and Chin, B. A. 1990. Monitoring joint penetration using infrared sensing techniques. Welding Journal 69(4): 181 -s to 185 -s.

20. Beardsley, H. E., Zhang, Y. M., and Kovacevic, R. 1994. Infrared sensing of full penetration state in gas tungsten arc welding. International Journal of Machine Tools and Manufacture 34(8): 1079-1090. DOI: 10.1016/0890-6955(94)90014-0.

21. Lucas, W., and Rodwell, M. H. 1987. Process techniques to improve control of weld penetration in TIG welding. Welding Review 6(3): 185-196.

22. Bicknell, A., Smith, J. S., and Lucas, J. 1994. Arc voltage sensor for monitoring of penetration in TIG welds. IEE Proceedings Science, Measurement and Technology 141(6): 513-520. DOI:

10.1049/ip-smt:19941144.

23. Li, X. R., Shao, Z., Zhang, Y. M., and Kvidahl, L. 2013. Monitoring and control of penetration in GTAW and pipe welding. Welding Journal 92(6): 190-s to 196-s.

24. Maram, J. M., and Smith, M. A. 1988. Optical weld contour monitor for penetration control. US Patent: US4767911A.

25. Song, H. S., and Zhang, Y. M. 2008. Measurement and analysis of three-dimensional specular gas tungsten arc weld pool surface. Welding Journal 87(4): 85-s to 95-s.

26. Zhang, W., Liu, Y., Wang, X., and Zhang, Y. 2012. Characterization of three-dimensional weld pool surface in GTAW. Welding Journal 91(7): 195-s to 203-s.

27. Zhang, W. J., and Zhang, Y. M. 2012. Modeling of human welder response to 3D weld pool surface: Part I - Principles. Welding Journal 91(11): 310-s to 318-s.

28. Zhang, W. J., and Zhang, Y. M. 2012. Modeling of human welder response to 3D weld pool surface: Part II - Results and analysis. Welding Journal 91(12): 329-s to 337-s.

29. Liu, Y. K., and Zhang, Y. M. 2013. Control of 3D weld pool surface. Control Engineering Practice 21(11): 1469-1480. DOI: 10.1016/j.conengprac.2013.06.019.

30. Liu, Y. K., and Zhang, Y. M. 2014. Model-based predictive control of weld penetration in gas tungsten arc welding. IEEE Transactions on Control Systems Technology 22(3): 955-966. DOI: 10.1109/TCST.2013.2266662.

31. Matsumoto, T., Misono, T., Fujii, H., and Nogi, K. 2005. Surface tension of molten stainless steels under plasma conditions. Journal of Materials Science 40(9): 2197-2200. DOI: 10.1007/ s10853-005-1932-9.

32. Shi, Y., Zhang, G., Ma, X. J., Gu, Y. F., Huang, J. K., and Fan, D. 2015. Laser-vision-based measurement and analysis of weld pool oscillation frequency in GTAW-P. Welding Journal 94(5): 176-s to 187-s.

33. Yu, S., Chunkai, L., Leiming, D., YuFen, G., and Ming, Z. 2016. Frequency characteristics of weld pool oscillation in pulsed gas tungsten arc welding. Journal of Manufacturing Processes 24: 145-151. DOI: 10.1016/j.jmapro.2016.08.010.

34. Zhang, K., Zhang, Y. M., Chen, J. S., and Wu, S. J. 2017. Observation and analysis of three-dimensional weld pool oscillation dynamic behaviors. Welding Journal 96(5): 143-s to 153-s.

35. Chen, J. 2017. Real-time sensing and control of developing weld penetration through reflection vibration in GTAW. Dissertation. Electrical Engineering Department, University of Kentucky. DOI: 10.13023/ETD.2017.046.

36. Ray, S. F., Jacobson, R. E., Attridge, G. G., and Axford, N. 2000. The Manual of Photography: Photographic and Digital Imaging. Elsevier Science \& Technology. 